\title{
The Unisa KZN Students' Perspectives of Student Success
}

\section{Phewa, Nombulelo}

Counselling and Career Development, University of South Africa, South Africa.

\begin{abstract}
This paper aims to present what students refer to as 'student success' based on their own lived experiences and perceptions. It also aims at presenting a proposal towards developing an integrated model for learner support whose objective is to identify students' academic and career needs at the point of entry; refer them to appropriate learning and career development programmes; and thereafter enrol them in a job readiness training and placement programme (JRTP) in preparation for work-integrated learning (WIL) placements.
\end{abstract}

A mixed methods study was conducted, involving a diagnostic academic literacies assessment, student questionnaires as well as focus group discussions. Participants were the KwaZulu-Natal (KZN)-based Unisa students who had been placed in WIL programmes with and/or without the career development and JRTP experience, and those that had been placed in other jobs not directly related to their qualifications and/or career needs through the JRTP programme.

It was found that most senior students view student success as obtaining a qualification, and being able to use such qualification in gainful employment, whereas junior students placed most emphasis on obtaining a qualification. It was also found that most of the JRTP students perceived the programme as having been helpful in them landing and retaining jobs.

Keywords: Academic Development ; Career Development; Job Readiness Training \& Placement; Success. 


\section{Introduction}

This paper aims at proposing a development of an integrated model for learner support whose objective is to identify students' academic and career needs at the point of entry; refer them to appropriate learning and career development programmes; and thereafter enrol them in a job readiness training and placement programme (JRTP) in preparation for work-integrated learning (WIL) placements.

\section{Research Questions}

The fact that the high unemployment rate in SA is not only limited to the uneducated and unskilled youth, but includes a large number of university graduates, raises a number of questions, which I thought I might be able to interrogate through this study. Also, the fact that Unisa has what I would like to believe is a strong learner support system (with Academic Development (AD) programmes, tutors, mentors, peer collaborative learners, etc.) and a mediocre throughput rate, added to the questions alluded to above, which are enumerated below.

The questions I have posed are:

1. Could it be that the unimpressive Unisa throughput rates (Unisa HEMIS, 2013) may be due to $\mathrm{AD}$ interventions that are generic and not related to the students' academic and career related needs?

2. Could it be that students are placed in work-seeking situations without being prepared at least for the 'soft skills' required in the world of work and hence the unemployability which might be the cause of the high rates of unemployed graduates?

3. Is there any contribution made by job preparation and career development initiatives towards students' graduateness and employability?

The general aims of the proposed study are firstly to find from Unisa students, who have been employed for at least 3 years, what their perceptions are of how they landed and kept their jobs, and whether or not they had participated in the JRTP and/or WIL programmes. Secondly, I would like to find out from the students what they perceive as student success and to what they ascribe that success to.

In the following paragraph I provide a summarised account of the literature I have reviewed. This review deals with the different ways in which the concept 'success' has been defined by the different scholars in their different contexts. It also deals with student preparation for the world of work, the soft skills imparted to them in such training, as well as studies related to WIL, and how these relate to increased academic performance. 


\section{Literature Review}

The aim of this review is to provide guidance to the study as well as serve as a basis for comparison between its findings and those of previous studies. As stated previously, I hope to shed some light on the questions of student preparation for the world of work, as well as provision of academic and career development interventions, which are not related to students' needs.I am also interested in the students' own perception of 'student success'.

I have therefore selected studies on the basis of how closely they address, in different contexts, questions similar to those posed by this current study as well as those relating to the aims of the proposed study, as has already been stated in the paragraph above. These relate to student success, graduate employability and employment preparation.

\subsection{Student success}

Numerous studies on student retention and throughput portray a 'single-minded' view of student success, that which measures it as successfully attaining a qualification and thus graduating from institutions of higher learning (Jones-White, Radcliffe, Huesman (Jnr), \& Kellog, 2010; Pauw, Bhorat, Goga, Ncube, \& van der Westhuizen, 2009; Tinto, 2012; Lee Harvey, 2010). This view of student success has been labelled as being institution-centred rather than being student-centred (Jones-White et al, 2010). This is what Jennings, Lovett, Cuba, Swingle and Lindkvist (2013) so eloquently capture in the following statement:

[W] will have done our job if our graduates lose themselves in 'general enthusiasms' in 'intellectual discovery' or 'make a difference in the world'.... (2013; 1).

Most studies revealed that students do not measure their success by the same tools their institutions do, and neither do they view it using the same lenses (Gonsalves and Vijaya, 2008; Cuseo, 2011; Jennings et al, 2013). It has emerged that students have different ways of 'defining' student success, with emphasis being differentially located. For example, in the Jennings et al study, students list multiple themes when asked to define success in college $\ldots$ their focus on their success narratives ebbs and flows over time $(2013 ; 6)$. Whilst Cuseo, (2011; 23) defines student success as:

[A] holistic phenomenon that embraces the multiple dimensions of personal development and the multiple goals of higher education. 


\subsection{Graduate Employability}

Knight and Yorke, 2004 define graduate employability as

"a set of achievements, understandings and personal attributes that make individuals more likely to gain employment and be successful in their chosen occupations" (22).

This definition seems to link directly employability to academic success and personal development and may therefore suggest that for individuals to attain employability, they may need to be educated. This notion seems to be supported by numerous researchers as indicated below.

Both national and international studies on student perceptions and opinions regarding graduate unemployment suggest that students see it as the function of institutions of higher learning to ensure that on qualification, they are employable (Wu, 2011; Pauw et al, 2009; Tomlinson, 2008), as suggested by the following extract:

The results indicate that undergraduates strategically arranged their courses so as to increase their employability to cope with the high college graduate unemployment rate, even though the practical and credential-related courses that they favoured resulted in heavier course loads. Evidently, undergraduates took initiative in increasing and developing their working competencies and employability to strengthen their future competitiveness in a cutthroat labor market (Wu, 2011; 308).

The recommendations from the Lowden, Hall, Elliot and Lewin (2011) study also link the functions of the institutions of higher learning to the development of graduate employability. Lee Harvey $(2000 ; 14)$ sums up the interface between higher education and the world of work,) by stating that:

The 'New Realities' that ask searching questions about the relationship between higher education and employment are, incidentally, asking about the purpose and structure of higher education.

\subsection{Graduate Employment Preparation}

Studies reviewed reveal that participants in graduate employment preparation programmes reported positive experiences with these, citing the benefits of having undergone such training (Lowden et al, 2011; McKinnon and Wood, 2012). According to these authors, the employers too reported satisfaction with the skills expected of the new graduate intake so much that some expressed that they reportedly appreciated the knowledge transfer opportunity and valued their work with the students as a useful recruitment tool. 


\section{Methodology}

In this section I provide summaries of how I have conducted the study in terms of research design, sampling and data generation and analysis methods applied. I detail these summaries below in the order stated so as to elucidate how I would extract the participants' perceptions and lived experiences, as I wanted to find out what I perceive as having been either helpful or not in their university preparation for academic preparedness and the world of work. I provide an account of the chosen research design below, in the following paragraph.

\subsection{Research design}

This is a mixed methods study which is hoped to contribute towards development of an integrated learner support model. For the qualitative part of the study I employed a phenomenological methodological framework, which have been consistently applied right through the phases of the study. I am aware of my assumptions that institutions of learning should prepare students for a world of work as part of life-long learning as influenced in part by literature; and as such have bracketed these.

For the quantitative part, I have chosen a non-experimental design, specifically descriptive survey, as I believe that it has a close relationship with the phenomenological research. This belief is based on the assertion that descriptive survey is ...

...[T] he method of research that looks with intense accuracy at the phenomena of the moment and then describes precisely what the researcher sees Leedy $(1997,190)$.

I also administered a diagnostic assessment tool, which I envisage that if carried out in conjunction with career assessment as pre-requisite to admission, provides a learner profile for specific, needs-focused academic and career guidance, counselling, mapping and pathing interventions. In this way I hope to develop a model that seeks to provide information about learners' academic and career strengths and areas requiring further development, as well as their career orientation.

The sampling method I conducted is outlined in the paragraph below.

\subsection{Sampling}

I purposively selected a group of Unisa students who have been through the JRTP programme and have been placed at Unisa as employees for at least 3 years irrespective of their career choices and/or aspirations. This sample forms the first category of students. The second category comprises of Unisa students who had never been part of the JRTP but had been placed in jobs related to their career choices or at least in line with their studies at Unisa, either in internships, apprenticeships, learnerships etc. through the WIL programme. 


\subsection{Data generation/collection}

As stated previously in the aforegoing sections, this is a mixed methods approach to data generation/collection involving an on-line diagnostic academic literacies assessment, online surveys for the students as well as focus group discussions. I facilitated three focus group discussions for each of the two categories of students.

The data generation and collection methods imply investigating the participants' perceptions and lived experiences, and therefore lend themselves to a number of ethical considerations. I provide an account of how I dealt with these in the following section.

\subsection{Ethical considerations}

I was granted ethical clearance on submission of an application where I declared how I would ensure that participants give consent to partaking in the study by signing a consent letter. I also ensured participant anonymity by utilising pseudonyms for both participants and their institutions. In focus groups, participants were sworn to secrecy and/or confidentiality. None of the participants have been exposed to any kind of harm as a result of participating in the study. A sample of the consent letter is appended to this paper.

\subsection{Data analysis}

Qualitative data were analysed by utilising a computer aided qualitative data analysis software (CAQDAS) referred to as Atlas ti, whilst data obtained by quantitative means were analysed by Computer Aided Quantitative Data Analysis Software (CAQDAS) programmes referred to as SPSS and classical item analysis (CIA).

\section{Findings}

In this section I present findings of the study relating to student success, employability and employment preparation from the students' perspectives.

Students had different understandings or definitions of student success. Some seemed to perceive student success with the same lenses as most institutions of higher learning, especially the younger ones - obtaining a qualification. The older students added to their understanding of student success issues of life and citizenry such as reflected in the extract below:

"If Unisa offers us life-long learning, if I am to achieve success in that kind of learning, it should not end when I graduate, it should extend to my full contribution to the economy of the country... and that is by obtaining gainful employment" (BA Hons student )

I found it interesting that of the 120 students that responded, most refer to student success as a combination of academic success and finding employment on graduation as depicted by Figure 1 below. 


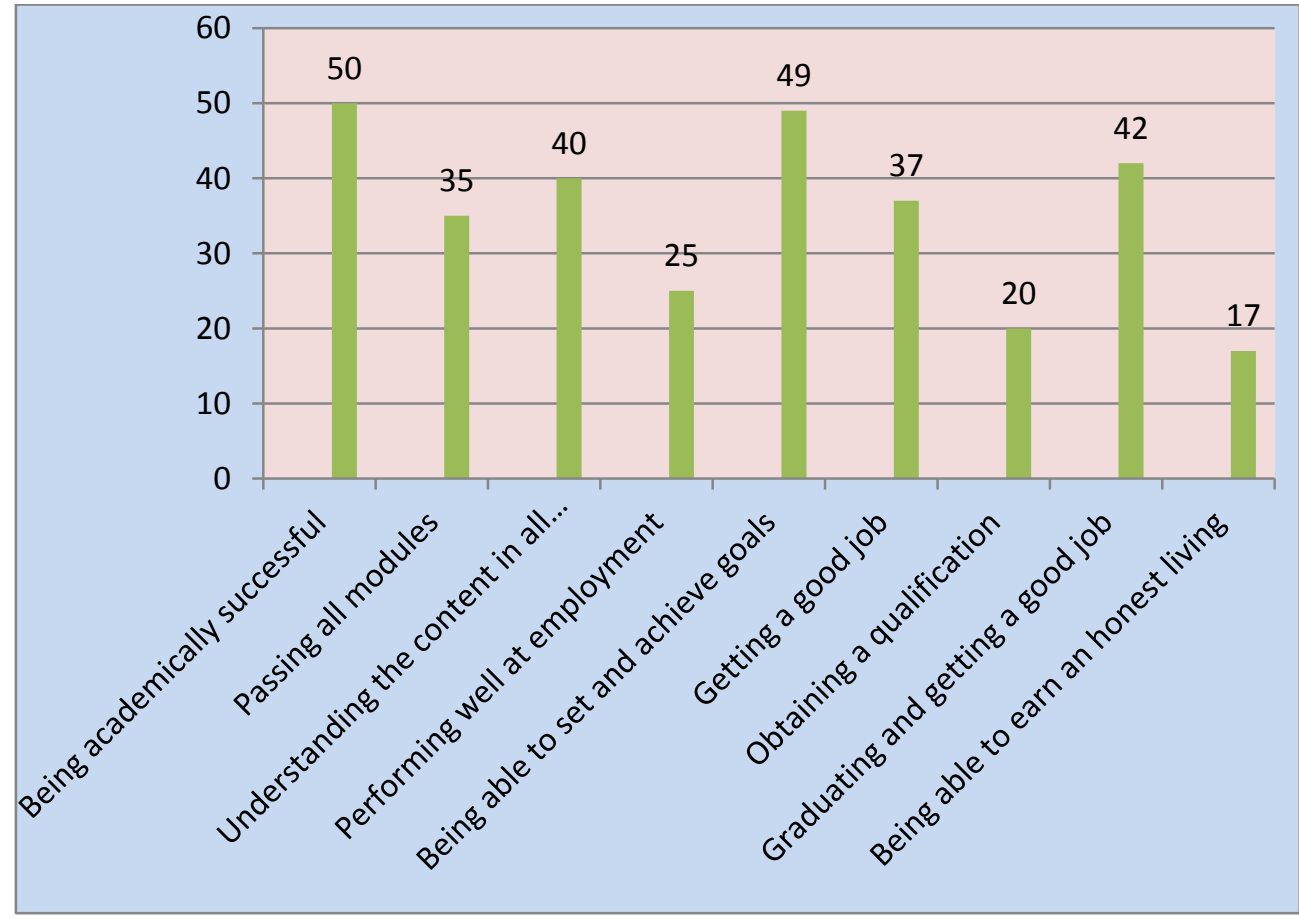

Figure 1: Illustration of what is stated in the paragraph above

This implies that students believe that university education should equip them with the kind of outcomes that can lead to being employed. Such findings corroborate the findings of some of the studies reviewed for this project (Cuseo, 2011; Gonsalves, 2008; Tomlinson, 2008; \& Lee Harvey, 2000).

Most of the students that have been exposed to the job readiness and placement programme reported positive experiences in their placement institutions including gaining experience they could use in future career-related employment.

\section{Conclusion}

Mixed methods study, though leaning heavily on phenomenology, is envisaged as appropriate in accommodating the best of both worlds of qualitative and quantitative research paradigms in terms of offering a rigorous approach to answering research questions (Creswell and Plano Clark, 2007).

It seems evident from the findings of this study that there is some measure of corroboration between previous studies and the current one with regards to the extended definition of 
student success as going beyond attaining a qualification. The most recent research undertaken in this regard, which was commissioned by the International Council for open and Distance Education, the ICDE (2015) also has similar findings as the current study. This relates to the student centred extended understanding of student success, where they asserted that employment outcomes form student success. Although the same cannot be said about employability, due to the complex nature of the phenomenon, the current study could not elucidate what the students' understanding of employability is. Most equated employability to employment.

Most students reportedly had mixed feelings about the work-related programmes. This might be due to the notion that Unisa does not seem to have a single consistent programme that deals with this issue. Those that had been through the JRTP programme sang praises for the intervention, whereas the same could not be said of those who had not been through this programme but had been only through the WIL programme.

It is safe to assume that an integration and institutionalization of the programmes would benefit both the students and the employers. It is envisaged that the JRTP programme, due to its nature of imparting 'soft skills' to the students, which most of the literature reviewed see as essential as a contribution towards employability, should be institutionalised and form part of the WIL programme. The integration of the programmes relating to academic and career development as well as job related prepation would ensure that students are supported academically and for employability, thus providing the expected outcomes of life-long learning.

\section{References}

Creswell, JW and Plano Clark, VL (2007) Designing and Conducting Mixed Methods Research, SAGE Publication, Thousand Oaks, California.

Cuseo, J. (2011) Defining Student Success: the Critical First Step in Promoting it, Esource College Transitions, National Resource Center for the First Year Experience and Students in Transition, University of South Carolina.

Gonsalves, SV; Vijaya, R (2008) First Year Students' Definitions of Success http://www.nyu.edu/frn/publications/defining.success/Gonsalves.Vijaya.html

Jennings, N.; Lovett, S; Cuba, L; Swingle, J and Lidkivst, H (2013) What Would Make this a Successful Year for You? How Students Define Success in College, https://www.aacu.org/publications-research/periodicals/what-would-make-successful-....

Jones-White, DR Radcliffe, PM, Huesman RL (Jnr), \& Kellog, JP (2010) Redefining Student Success: Applying Different Multinomial Regression Techniques for the Study of Student Graduation Across Institutions of higher Education, Res high Educ (2010) 51: 154 - 174 
Knight, P and Yorke, M (2004) Learning Curriculum and Employability in Higher Education, London, Routledge.

Lee Harvey (2000) New realities: The relationship between higher education and employment, Tertiary Education and Management, 6:1, 3-17, DOI: 10.1080/13583883.2000.9967007

Leedy, PD (1997) Practical Research Planning and Design (6th ed.), Merrill an imprint of Prentice Hall, Upper Saddle River, New Jersey.

Lowden, K; Hall, S Elliot, D and Lewin, J (2011) Employers' Perceptions of the Employability Skills of New Graduates, University of Glasgow SCRE Centre and Edge Foundation 2011

McKinnon, S and Wood, B (2012) Learning for the Real World: Preparing Postgraduate Design Students for Employment through Embedding Work-Related Learning in the Curriculum, Design Education for Future Wellbeing. Proceedings of the 14th International Conference on Engineering and Product Design Education, Artesis University College, Antwerp, Belgium 6th - 7th September 2012

Pauw, K; Bhorat, H; Goga, S; Ncube, L; van der Westhuizen, C (2009) Graduate Unemployment in the Context of Skills Shortages, Education and Training: Findings from a Firm Survey

Tinto, V (2012) An Introduction to Completing College - Rethinking Institutional Action, University of Chicago Press

Tomlinson, M (2008) The Degree is Not Enough: students' perceptions of the role of higher Education credentials for graduate work and employability, The British Journal of Sociology of Education, 29:1, pp49-61

Unisa (2013) An institutional profile: Unisa Facts \& Figures HEMIS 2008 - 2012, Unisa's Institutional Information and Analysis Portal. Available on the website of the University of South Africa, Department of Institutional Statistics and Analysis. Last search on November 2013. Available: http://heda.unisa.ac.za/

Wu, Chih-Chun (2011) High Graduate unemployment rate and Taiwanese undergraduate education, International Journal of Educational Development 31 (2011) 303 - 310 